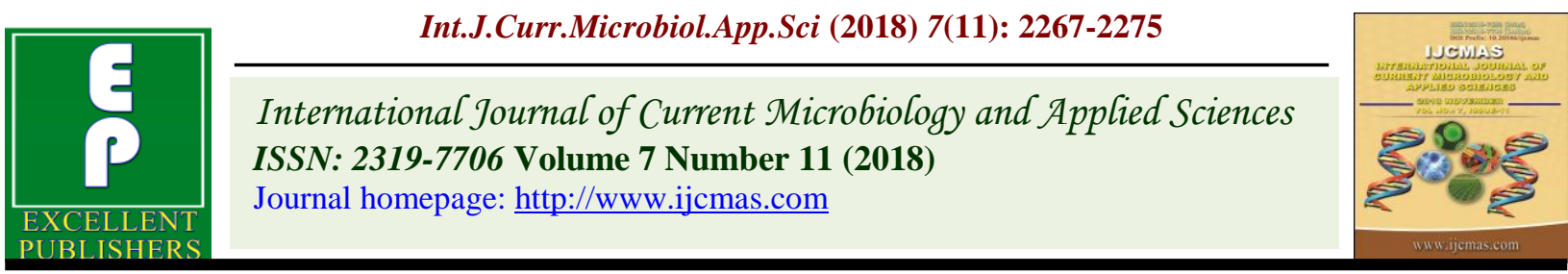

Original Research Article

https://doi.org/10.20546/ijcmas.2018.711.254

\title{
Molecular Mapping of QTLs for Zinc Deficiency Tolerance in Rice (Oryza sativa L.)
}

\author{
Elicherla Siva Sankar Reddy*, S.B. Verulkar and R.R. Saxena
}

Indira Gandhi Krishi Viswavidyalaya, College of Agriculture, Raipur, Chhattisgarh, India

*Corresponding author

\begin{abstract}
Keywords
Rice, Zinc

deficiency, QTLs, SSR markers

Article Info

Accepted:

18 October 2018

Available Online:

10 November 2018 burden on resource poor farmers. Present investigation was taken to map QTLs for zinc deficiency tolerance to zinc deficiency in rice which may helpful to develop zinc deficiency tolerant cultivars. Phenotypic data generated under rainfed zinc deficiency field condition using 271 recombinant inbred lines(RILs) derived from cross between two indica genotypes, Danteshwari and Dagad Deshi during wet season 2011 concluded that zinc deficiency tolerance as a polygenic trait. Bulk segregant analysis (BSA) and cosegregation analysis methods were used to generate genotypic data followed by single marker analysis with chi-square test along with Yates correction for molecular mapping of QTLs related to zinc deficiency tolerance. Three QTL linked with HvSSR 01- 80, HvSSR 01-87 and RM 499 markers identified on chromosome 1, two QTLs linked with RM 135 and RM 232 markers located on chromosome 3, one QTL linked with marker HvSSR 0531 present on chromosome 5, two QTLs linked with RM 242 and RM 296 on chromosome 9 and one QTL linked with marker RM 26334 located on chromosome 11 are contributing zinc deficiency tolerance based on the genotypic data.
\end{abstract}

A B S T R A C T

Zinc deficiency which leads to "Khaira" disease is the major micronutrient problem in rice. It can be corrected by applying zinc supplements to the soil or plant which will put

\section{Introduction}

"Rice is life"- This slogan of the international year of rice 2004, outlines the importance of rice. Rice (Oryza sativa L.) is the most important cereal crop that has been referred as "Global Grain" (Shalini and Tulasi, 2008) because of its use as prime staple food in about 100 countries of the world. Zinc is one of the essential nutrients for plants and its deficiency is one of the major micronutrient constraints to crop production throughout the world. It was first diagnosed in on calcareous soils of northern India (Nene, 1966; Yoshida and Tanaka, 1969). The "khaira" disease of India, "Hadda" of west Pakistan and "TayaTaya" of the Philippines have been known for a long time among local farmers though the causes were unknown.

However, this disorder was proved later as due to zinc deficiency (Tanaka, 1970). It has been associated with a wide range of soil conditions: high $\mathrm{pH}$ (7.0), low available zinc content, prolonged submergence and low redox potential, high organic matter and bicarbonate content, high magnesium $(\mathrm{Mg})$ to 
calcium $(\mathrm{Ca})$ ratio and high available $\mathrm{P}$ (Nene and Lantin, 1994).

Rice yield and growth is very sensitive to zinc and it can be corrected by adding zinc compounds to the soil or plant, but the high cost associated with applying zinc fertilizers in sufficient quantities to overcome zinc deficiency places considerable burden on resource-poor farmers and it has therefore been suggested that breeding efforts should be intensified to improve the tolerance to zinc deficiency in rice cultivars (Quijano-Guerta $e t$ al., 2002 and Singh et al., 2003).

In this study an attempt has been made to identify QTLs for tolerance to zinc deficiency in rice using Recombinant Inbred Line (RIL) mapping population with the help of microsatellite markers.

\section{Materials and Methods}

A Recombinant Inbred line population in $\mathrm{F}_{12}$ generation having 271 lines was developed from Danteshwari and Dagad Deshi (drought tolerant land race) as parents by using modified single seed descent method. In the present study, 271 lines of this RIL population along with parents were in the field during wet season 2011 at research cum instructional farm of College of Agriculture, IGKV, Raipur. The field trials were conducted under rainfed direct sown condition. Each genotype was sown in three rows of $2 \mathrm{~m}$ length and one line gap with spacing of $15 \mathrm{~cm}$ between rows. All the genotypes were replicated twice in RBD design.

\section{Scoring of zinc deficiency tolerance}

\section{Zinc deficiency scale (Anon, 2002)}

1 - Growth and tillering nearly normal; healthy

2 - Growth and tillering nearly normal; basal leaves slightly discolored

3 - Stunting slight, tillering decreased, some basal leaves brown or yellow

5 - Growth and tillering severely retarded, about half of all leaves brown or yellow

7 - Growth and tillering ceases, most leaves brown or yellow

9 - Almost all plants dead or dying

\section{Soil sampling}

Six soil samples were collected from the experimental field at different locations to know zinc nutrient present in the soil. These soil samples were analyzed in soil science laboratory by using Atomic Absorption Spectrophotometry (AAS). Readings of these samples were ranged between $0.5 \mathrm{ppm}$ to $1.0 \mathrm{ppm}$. Critical level of soil below which zinc deficiency might occur is 1.0ppm (Castro, 1977).

\section{Genomic DNA isolation}

A mini prep method was used to extract genomic DNA from selected lines along with parents. Approximately $2 \mathrm{~g}$ of young leaf material cut into the small pieces was transferred to $2 \mathrm{ml}$ centrifuge containing 500 $\mu 1$ of DNA extraction buffer along with small stainless steel beads. These tubes were fixed in tissue homolyzer (MO. BIO. powerlyzer 24) and it was operated in two cycles at $2400 \mathrm{rpm}$ about 2 minutes with 5 seconds pause between two cycles. After removing stainless steel beads from tubes, $400 \mu \mathrm{l}$ of 24:1 choloroform: Iso amyl Alcohol was mixed. Centrifugation of these tubes at 14000rpm for about four minutes gave super aqueous which was taken into new centrifuge tube. To the double of the super aqueous taken $100 \%$ chilled ethanol was added and it was kept at $-20^{\circ} \mathrm{C}$ for about 30 
minutes to precipitate the DNA. After that it was centrifuged at $14000 \mathrm{rpm}$ for about four minutes to settle the DNA as a pellet and later it was washed with $70 \%$ ethanol. At the end it was air dried and $100 \mu 1 \mathrm{TE}$ buffer was added to dissolve the DNA pellet. Each DNA sample was quantified and diluted to $20 \mathrm{ng} / \mu \mathrm{l}$ to proceed for PCR.

\section{Bulking of DNA samples for selective genotyping}

Diluted DNA (20ng/ $\mu \mathrm{l})$ from each eleven lines which were most tolerant and most susceptible to zinc deficiency was taken and prepared bulks as tolerant bulk lines (TBL) and susceptible lines (SBL) respectively as suggested by Michelmore et al., (1991).

\section{PCR and electrophoresis}

For amplification, SSR and HvSSR (Highly Variable SSR) markers were used. For DNA amplification, reaction mixture consisted of following in $20 \mu \mathrm{l}$ volume (Table 1) and temperature profile used for PCR amplification (Table 2). To each completed reaction $2 \mu \mathrm{l}$ of loading dye was added and they were electrophorosed in 5\% PAGE (Poly Acrylamide Gel Electrophoresis). After electrophoresis gels were stained with Ethidium Bromide (EtBr) for 4 minutes, washed with distilled water and photographed using gel doc unit (BIO RAD).

\section{Selective genotyping}

A total of 186 primers (110 SSR and 76 HvSSR) were used for genotyping. Primarily both the bulks along with parents were subjected to amplification using 186 primers. Among those primers, which were showing polymorphic along with parents were selected for co-segregation analysis. Single marker analysis was used to validate these markers. Statistical analysis
Single marker analysis by Chi square analysis with Yates correction was used for mapping the QTLs associated with these root traits.

\section{Results and Discussion}

Significant variation for zinc deficiency tolerance was noticed among recombinant inbred lines under rainfed condition. Screening was done in the field thirty days after sowing, according to scoring pattern given in the Standard Evaluation System (SES) (Anonymous, 2002). The scoring was done in the field when the differences for zinc deficiency were very clear with lines exhibiting a range of score from 1 to 9 . Among 271 RIL population, 11 lines were highly tolerant to zinc deficiency with score of 1 with absolutely no symptom of deficiency. 36 lines exhibited score of 3 , major portion of this RIL lines i.e.172 lines exhibited score of 5, 48 lines were susceptible while, 4 lines were highly susceptible. The above data is showing continuous variation. Out of total 271 lines, 11 extreme susceptible lines $(16,78,80$, $89,149,156,191,220,229,259,269)$ and 11 extreme tolerant lines $(10,26,70.72,74,105$, $106,139,140,174,245)$ were subsequently used for further analysis.

\section{Development of genotypic data using HvSSR and SSR markers}

RIL populations are genetically true-breeding or homozygosity, stable and permanent and well suited to QTL analysis. Further, RILs undergoes multiple round of meiosis before homozygosity is reached, there is a greater chances for linked gene to recombine, providing an opportunity for accurate detection of QTLs (Burr and Burr, 1991; McCouch and Doerge, 1995). After standardization of the PCR protocol for SSR assay, it was used for all subsequent studies. BSA and co-segragtion analysis were used to generate genotypic data using HvSSR and 
SSR markers. The markers were taken from previously published rice genetic and sequence maps (Singh et al., 2009; McCouch et al., 2002; Temnykh et al., 2001).

\section{Bulk Segregant Analysis (BSA)}

In this analysis, DNA isolated from each eleven tolerant lines and each eleven susceptible lines was pooled to generate tolerant bulk and susceptible bulks,

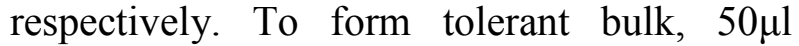
diluted DNA $(20 \eta \mathrm{g} / \mu \mathrm{l})$ from all eleven tolerant lines were pooled into one eppendorff tube as suggested by Michelmore et al., 1991 .

To form susceptible bulk, $50 \mu \mathrm{l}$ of diluted DNA $(20 \eta \mathrm{g} / \mu \mathrm{l})$ from all eleven susceptible lines were pooled into new eppendorf tube. In this analysis, both the parents along with the two bulks (tolerant and susceptible) were used for amplification of genomic DNA through
PCR. PCR products were loaded on 5\% PAGE and electrophoresis was used to run and gels were visualized and photographed by using Gel Doc Unit (BIO RAD). Out of $186 \mathrm{HvSSR}$ and SSR markers, only 14 markers showed parental polymorphism along with polymorphism in respective bulks. Only $7.5 \%$ (14 markers) out of 186 markers used exhibited polymorphism. The low level of polymorphism may be probably the indica $x$ indica cross used in this study. The level of polymorphism was lower than that observed for mapping parents in studies by Bernier et al., (2007) using Vandana and Way Rarem as parents. The relatively low recovery of parental polymorphism under this study was attributable to the narrow genetic variation between the parents as both of these were indica type and adopted to grow in the same rice ecosystem. Gel pictures showing poly morphic bulk segregation along with parents for some primers were presented in plate 1 .

Table.1 PCR mix for one reaction (Volume $20 \mu \mathrm{l}$ )

\begin{tabular}{|l|l|l|}
\hline Reagent & Stock concentration & Volume $(\mu \mathrm{l})$ \\
\hline 1) $\mathrm{Nanopure} \mathrm{H}_{2} \mathrm{O}$ & - & 13.3 \\
\hline 2) $\mathbf{P C R}$ buffer & $10 \mathrm{X}$ & 2.0 \\
\hline 3) $\mathbf{M g C l}_{2}$ & $15 \mathrm{mM}$ & 0.5 \\
\hline 3) $\mathbf{d N T P s}($ Mix) & $10 \mathrm{mM}$ & 1.0 \\
\hline 4) Primer (forward) & $5 \mathrm{pmol}$. & 0.5 \\
\hline 5) Primer (reverse) & $5 \mathrm{pmol}$. & 0.5 \\
\hline 6) $\mathrm{Taq}$ polymerase & $5 \mathrm{unit} / \mu \mathrm{l}$ & 0.2 \\
\hline 7) DNA template & $20 \eta \mathrm{g} / \mu \mathrm{l}$ & 2.0 \\
\hline Total & & $\mathbf{2 0}$ \\
\hline
\end{tabular}

Table.2 Temperature profile used for PCR amplification using microsatellite markers

\begin{tabular}{|c|c|c|c|c|}
\hline Steps & Temperature $\left({ }^{\circ} \mathrm{C}\right)$ & Duration (min.) & Cycles & Activity \\
\hline 1 & 95 & 5 & 1 & Denaturation \\
\hline 2 & 94 & 1 & & Denaturation \\
\hline 3 & 55 & 1 & 34 & Annealing \\
\hline 4 & 72 & 2 & & Extension \\
\hline 5 & 72 & & & Final Extension \\
\hline 6 & 4 & $24 \mathrm{hrs}$ & 1 & Storage \\
\hline
\end{tabular}


Table.3 Chi square $\left(\chi^{2}\right)$ analysis with Yates correction

\begin{tabular}{|c|c|c|c|c|c|}
\hline \multirow[t]{2}{*}{ Markers } & \multicolumn{2}{|c|}{$\begin{array}{l}\text { observed values for } \\
\text { susceptible lines }\end{array}$} & \multicolumn{2}{|c|}{$\begin{array}{l}\text { observed values for } \\
\text { tolerant lines }\end{array}$} & \multirow{2}{*}{$\begin{array}{l}\text { Chi square } \\
\text { value with } \\
\text { Yates } \\
\text { correction }\end{array}$} \\
\hline & A-type (a) & B-type (b) & A-type (c) & B-type (d) & \\
\hline HvSSR 01-80 & 11 & 0 & 2 & 9 & $12.03 *$ \\
\hline HvSSR 01-87 & 11 & 0 & 6 & 5 & $4.14^{*}$ \\
\hline HvSSR 01-89 & 8 & 0 & 6 & 5 & 3.00 \\
\hline HvSSR 03-40 & 7 & 2 & 3 & 7 & 2.78 \\
\hline HvSSR 04-35 & 8 & 1 & 2 & 4 & 2.94 \\
\hline HvSSR 05-31 & 8 & 0 & 2 & 5 & $6.60^{*}$ \\
\hline RM 17 & 7 & 1 & 5 & 6 & 2.01 \\
\hline RM 242 & 8 & 0 & 2 & 8 & $9.65^{*}$ \\
\hline RM 135 & 11 & 0 & 3 & 7 & $8.88^{*}$ \\
\hline RM 499 & 9 & 1 & 2 & 5 & $4.87 *$ \\
\hline RM 232 & 7 & 3 & 2 & 9 & $3.91 *$ \\
\hline RM 296 & 10 & 1 & 3 & 7 & $6.03 *$ \\
\hline RM 278 & 7 & 3 & 3 & 8 & 2.35 \\
\hline RM 26334 & 7 & 0 & 0 & 7 & $13.23 *$ \\
\hline
\end{tabular}

Here (a), (b), (c), (d) are taken as variables in $2 \times 2$ contingency tables to substitute in the formula. $\chi^{2}$ value at 0.05 level of probability. 
Plate.1 Gel images showing bulk segregant analysis

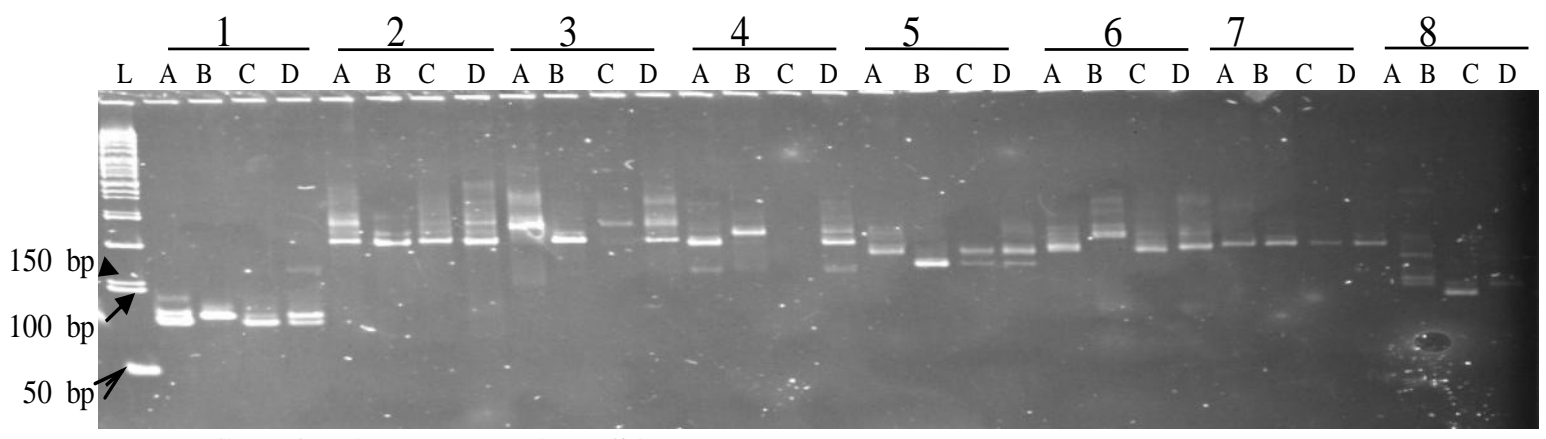

ssr profile of primers used in BSA

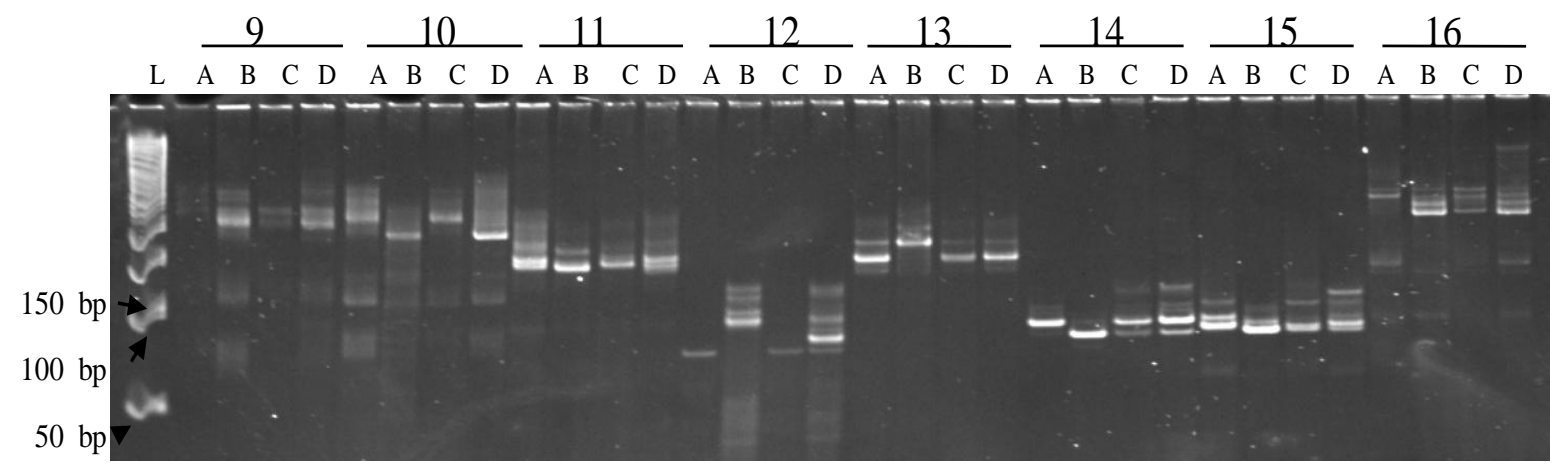

ssr profile of primers used in BSA

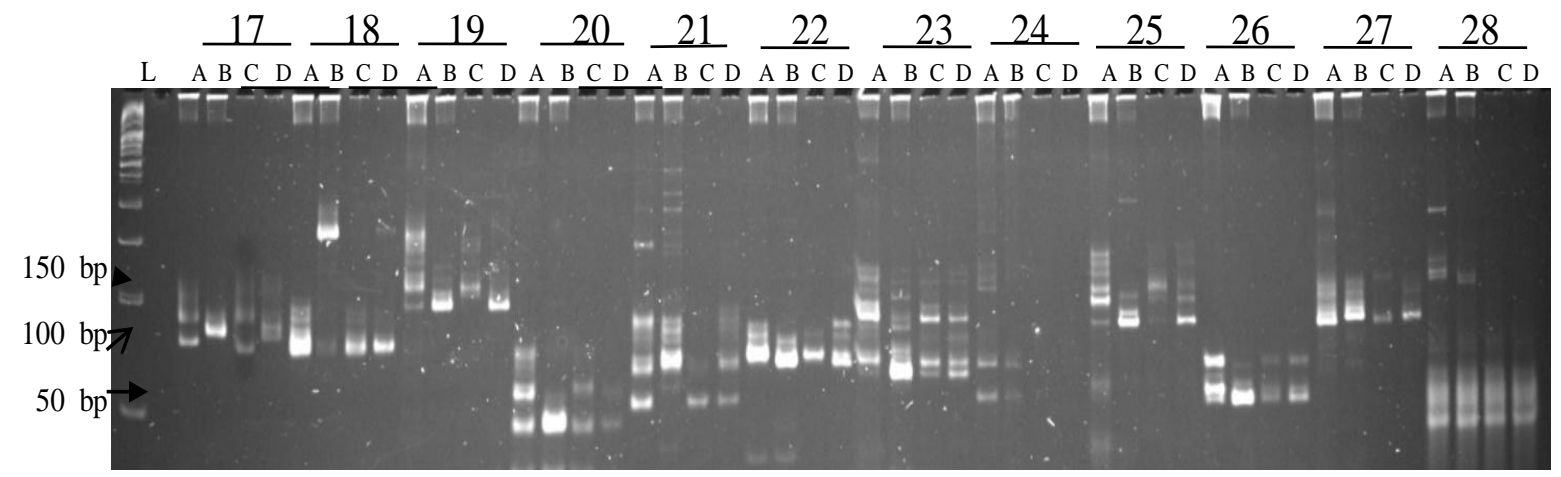

ssr profile of primers used in BSA

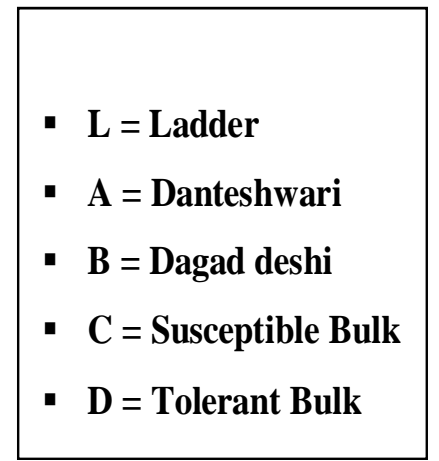

\begin{tabular}{|c|c|c|}
\hline $\begin{array}{ll}\text { Primers: } \\
\text { 1. HvSSR 04-26 } \\
\text { 2. HvSSR 04-32 } \\
\text { 3. HvSSR 04-35 } \\
\text { 4. HvSSR 04-38 } \\
\text { 5. HvSSR 04-39 } \\
\text { 6. HvSSR 04-42 } \\
\text { 7. HvSSR 05-12 } \\
\text { 8. } & \text { HvSSR } 05-13\end{array}$ & $\begin{array}{ll}\text { 9. } & \text { HvSSR 05-23 } \\
\text { 10. } & \text { HvSSR 05-31 } \\
\text { 11. } & \text { HvSSR 05-39 } \\
\text { 12. } & \text { HvSSR 05-48 } \\
\text { 13. } & \text { HvSSR 05-51 } \\
\text { 14. } & \text { HvSSR 05-52 } \\
\text { 15. } & \text { HvSSR 05-56 } \\
\text { 16. } & \text { HvSSR 05-65 }\end{array}$ & $\begin{array}{ll}\text { 17. } & \text { RM 17 } \\
\text { 18. } & \text { RM } 201 \\
\text { 19. } & \text { RM 242 } \\
\text { 20. } & \text { RM } 243 \\
\text { 21. } & \text { RM } 256 \\
\text { 22. } & \text { RM 278 } \\
\text { 23. } & \text { RM } 281 \\
\text { 24. } & \text { RM } 315 \\
\text { 25. } & \text { RM } 410 \\
\text { 26. } & \text { RM 411 } \\
\text { 27. } & \text { RM } 444 \\
\text { 28. } & \text { RM 492 }\end{array}$ \\
\hline
\end{tabular}


Plate.2 Gel images showing co-segregation analysis

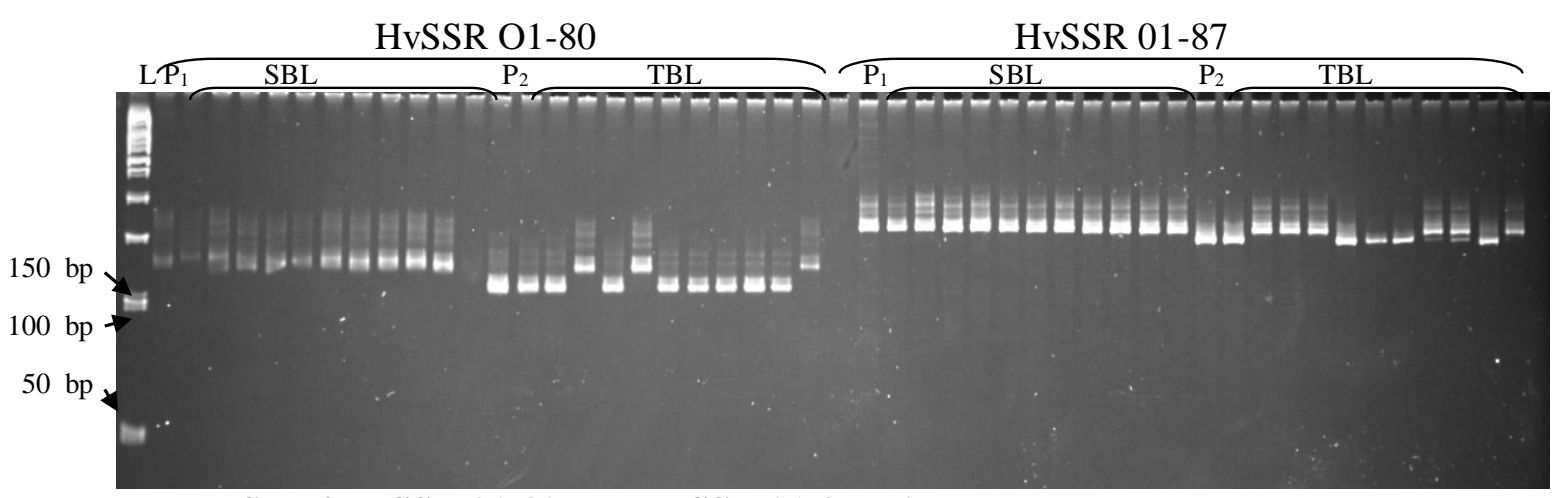

ssr profile of HvSSR 01-80 and HvSSR 01-87 primers

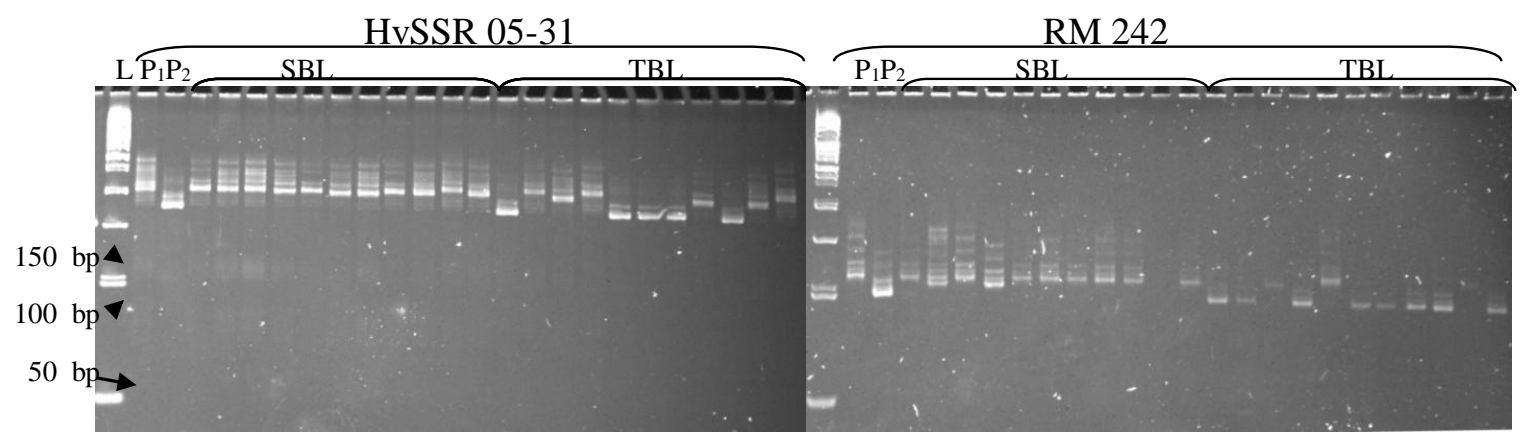

ssr profile of HvSSR 05-31 and RM242 primers

$$
\begin{array}{ll}
\text { - } & \text { L = Ladder } \\
\text { - } & \text { P1 = Danteshwari } \\
\text { - } & \text { P2 = Dagaddeshi } \\
\text { - } & \text { SBL }=\text { Susceptible Bulk Lines } \\
\text { - } & \text { TBL = Tolerant Bulk Lines }
\end{array}
$$

\section{Co-segregation analysis}

The primers showing desired bulk segregation were selected and subsequently used for PCR amplification of each and every line of bulk along with parents (co-segregation analysis) using standardized PCR protocol. The PCR products were loaded on 5\% PAGE and run at 180 volts for about one hour. Then it was stained with Ethidium bromide (EtBr) solution, and visualized and photographed by using Gel Doc Unit (BIO RAD). The bands observed were designated as $\mathrm{A}, \mathrm{B}$ and $\mathrm{E}$ where $\mathrm{A}$ represents female parent like allele, $B$ represent male

\section{Susceptible Bulk Lines (from left to right)}

$16,78,80,89,149,156,191,220,229,259,269$

Tolerant Bulk Lines (from left to right)

$10,26,70,72,74,105,106,139,140,174,245$

parent like allele, E represents other type allele (which is not normally expected in RIL population). Gel images of co-segregation analysis for HvSSR 01-80, HvSSR 01-87, HvSSR 05-31, RM 242 are presented in plate 2.

\section{QTLs identification}

For QTL identification selective genotyping was done by selecting extreme phenotypic classes. Test for QTL association was performed by single marker approach. For single marker analysis, chi-square test analysis with Yates correction was followed to find out 
significant and non-significant association between trait and markers. Results of chi-square test analysis are presented in Table 3 . Since the population used in the study includes the fixed homozygous lines in $F_{12}$ generation therefore theoretical expected ratio between $\mathrm{A}$ and $\mathrm{B}$ banding pattern of lines should be 1:1 as per Hardy Weinberg equilibrium (Mendelian segregation without any linkage). Any significant deviation from this ratio indicates the disequilibrium of banding pattern.

This disequilibrium is expected if the marker is closely located to the gene of interest, as the complete set of population was selected for one trait in its extreme form. Chi square $\left(\square^{2}\right)$ value was deviated from the normal ratio and found significant from table value for nine primers among total fourteen primers showing bulk segregation analysis polymorphism, they are HvSSR 01-80, HvSSR 01-87, HvSSR 05-31, RM 242, RM 135, RM 499, RM 232, RM 296 and RM 26334. These are the nine primers deviated from normal Mendelian segregation ratio and they are supposed to be linked with the zinc deficiency tolerance.

HvSSR 05-31 primer present on chromosome 5 located at $13.46 \mathrm{cM}$ contributing zinc deficiency tolerance QTL, did not matched with the region obtained for zinc deficiency tolerance to Avendano (2000) showing that $61.9 \%$ variation with LOD value 3.45 on chromosome 5 between marker interval RM 164 and RM 87.

RM242 and RM296 primers present on chromosome 9 at locus $73.3 \mathrm{cM}$ and $20.4 \mathrm{cM}$ respectively were also found to be linked with QTLs for zinc deficiency tolerance. Ramya et al., (2010) reported that the region between RM160 - RM215 on chromosome 9, contributing to maximum root depth under both control and drought stress condition. Primers RM242 and RM296 linked with zinc deficiency tolerance on chromosome 9 lying between marker interval RM160 - RM215. In present investigation, according to root scan data obtained from samples collected from field condition showing tolerance had more root length and root volume (unpublished data), which indicated that zinc deficiency tolerance character is directly or indirectly associated with the root length and root volume.

Traits associated with markers were observed from gramene data base (www.gramene.org) and cerealab database (www.cerealab.org), which also revealed that RM242 is associated with more root related traits. Mathews (2005) reported that available zinc was maximum at the surface and decreased with depth. Based on this, in the present investigation, resistant lines having more root length and volume can be claimed to get corresponding nutrients very easily than the lines having less root length and volume.

From the above discussion, it was concluded that QTLs are associated with nine markers (HvSSR 01-80, HvSSR 01-87, HvSSR 05-31, RM242, RM135, RM499, RM232, RM296 and RM26334) for zinc deficiency tolerance, among them RM242 is the marker that is associated with root length and volume (Ramya et al., 2006.) and zinc deficiency tolerance.

\section{References}

Anonymous, 2002. Standard Evaluation System. IRRI. pp. 1-56

Avendano, B.S. 2000. Tagging high content in the grain and zinc deficiency tolerance genes in rice (Oryza sativa L.) using simple sequence repeats (SSR). Thesis submitted to university of Philippines at Las banos.

Bernier, J., Kumar, A., Ramiah, V., Spaner, D. and Atlin, G. 2007. A large effect of QTL for grain yield under reproductive stage drought stress in upland rice. Crop Sci., 47: 505-518.

Burr, B. and Burr, F.A. 1991. Recombinant inbreds for molecular mapping in maize. Trends in Genet., 7: 55-60.

Castro, R.U. 1977.Zinc deficiency in rice:A review of research at the International 
Rice Research Institute.I RRI res.pap.ser.9, pp. 1-12.

Mathews, D.V. 2005. Response of rice to soil fertility constraints and Bio-fertilizers in coastal alluvial soil of Karnataka. M.Sc. Thesis, UAS, Dharwad.

McCouch, S.R. and Doerge, R.W. 1995. QTL mapping in rice. TIG., 11(12): 482-487.

McCouch, S.R., Teytelman, L., Xu, Y., Lobos, K.B., Clare, K., Walton, M., Fu, B., Maghirang, R., Li, Z., Xing, Y., Zhang, Q., Kono, I., Yano, M., Fjellstrom, R., DeClerck, G., Schneider, D., Cartinhour, S., Ware, D. and Stein, L. 2002. Development and mapping of 2240 new SSR markers for rice (Oryza sativa L.). DNA Res., 9: 257-279.

Michelmore, R. W., Paran, I., and Kesseli, R. V. 1991. Identification of markers linked to disease-resistance genes by bulked segregant analysis: A rapid method to detect markers in specific genomic regions by using segregating populations. Proc. Natl. Acad. Sci. USA, 88: 98289832.

Nene, Y.L. 1966. Symptoms, cause and control of Khaira disease of paddy. Bull. Indian Phytopathol Soc. 3: 97-191.

Neue, H.U. and Lantin, R.S. 1994. Micronutrient toxicities and deficiencies in rice. In AR Yeo, TJ Flowers, eds, Soil mineral stresses: approaches to crop improvement. Springer-Verlag, Berlin, Germany, pp. 175-200.

Quijano-Guerta, C., Krik, G.J.D, Portugal, A.M, Bartolome, V. and Mclaren, G.C. 2002. Tolerance of rice germplasm to $\mathrm{Zn}$ deficiency. Field Crops Res. 76: 123-130.
Ramya, M., Raveendran, M., Sathiyamoorthy, S. and Ramalingam, J. 2010. In silico analysis of drought tolerance genes in rice. Int. J. of Bio. \& Med. Res., 1(3): 3640.

Shalini, P. and Tulasi, T. 2008. Production potential and nutrient use efficiency of basmati rice (Oryza sativa L.) under integrated nutrient management. Green Farming, 1(9): 11-13.

Singh, B., Natesan, S.K.A., Singh, B.K. and Usha, K. 2003. Improving Zn efficiency of cereals under Zn deficiency. Curr. Sci., 88: 36-44.

Singh, H., Deshmukh, R.K., Singh, A., Singh, A.K., Gaikwad, K., Gaikwad, T., Sharma, T.R., Mohapatra, T. and Singh, N.K. 2009. Highly variable SSR markers suitable for Rice genotyping using Agarose gels. Mol. Breed., 25(2): 359364.

Tanaka, A. and Yoshida. S. 1970. Nutritional disorders of the rice plant in Asia. Int. Rice Res. Inst. Tech. Bull., 10: 31-40.

Temnykh, S., DeClerk, G., Lukashova, A., Lipovich, L., Cartinhour, S. and McCouch, S.R. 2001. Computational and experimental analysis of microsatellites in rice (Oryza sativa): frequency, length variation, transposon associations and genetic marker potential. Genome Res., 11: 1441-1452.

www.cerealab.org

www.gramene.org

Yoshida, S. and Tanaka, A. 1969. Zinc deficiency of the rice plant in calcareous soils. Soil Sci. Plant Nutr., 15: 75-80.

\section{How to cite this article:}

Elicherla Siva Sankar Reddy, S.B. Verulkar and Saxena, R.R. 2018. Molecular Mapping of QTLs for Zinc Deficiency Tolerance in Rice (Oryza sativa L.). Int.J.Curr.Microbiol.App.Sci. 7(11): 22672275. doi: https://doi.org/10.20546/ijcmas.2018.711.254 